\title{
Associations between genetic variants located in mature microRNAs and risk of lung cancer
}

\author{
Dengrui Li ${ }^{1, *}$, Guiyun Zhu ${ }^{2,}{ }^{*}$, Hongqin $\mathrm{Di}^{3}$, Hui $\mathrm{Li}^{4}$, Xinyan Liu ${ }^{5}$, Min Zhao ${ }^{6}$, Zhihua \\ Zhang7, Yonghui Yang ${ }^{2}$ \\ ${ }^{1}$ Department of General Internal Medicine, Chest Hospital of Hebei Province, Lung Cancer Prevention and Control Center of \\ Hebei Province, Shijiazhuang, Hebei, China, 050041 \\ ${ }^{2}$ Department of Pathology, Chest Hospital of Hebei Province, Lung Cancer Prevention and Control Center of Hebei Province, \\ Shijiazhuang, Hebei, China, 050041 \\ ${ }^{3}$ Clinical Laboratory, Chest Hospital of Hebei Province, Lung Cancer Prevention and Control Center of Hebei Province, \\ Shijiazhuang, Hebei, China, 050041 \\ ${ }^{4}$ Department of Thoracic Surgery, Chest Hospital of Hebei Province, Lung Cancer Prevention and Control Center of Hebei \\ Province, Shijiazhuang, Hebei, China, 050041 \\ ${ }^{5}$ The First Department of Oncology, Chest Hospital of Hebei Province, Lung Cancer Prevention and Control Center of Hebei \\ Province, Shijiazhuang, Hebei, China, 050041 \\ ${ }^{6}$ The Second Department of Oncology, Chest hospital of Hebei Province, Lung Cancer Prevention and Control Center of Hebei \\ Province, Shijiazhuang, Hebei, China, 050041 \\ ${ }^{7}$ Medical Department, Chest Hospital of Hebei Province, Lung Cancer Prevention and Control Center of Hebei Province, \\ Shijiazhuang, Hebei, China, 050041 \\ *These authors contributed equally to this work
}

Correspondence to: Yonghui Yang, email: yangyonghuihb@126.com

Keywords: microRNAs, lung cancer, variant

Received: January 17, $2016 \quad$ Accepted: May 12, $2016 \quad$ Published: May 24, 2016

\section{ABSTRACT}

MiRNAs have been focused for their wide range of biological regulatory functions. Previous studies have suggested that individual miRNAs could influence tumorigenesis through their regulation of specific proto-oncogenes and tumor suppressor genes. This study was implemented to investigate the associations between SNPs in mature microRNAs (miRNAs) and development of lung cancer in a two-stage, case-control study, followed by some functional validations. First, 11 SNPs were analyzed in a case-control study of lung cancer, and the significant results were validated in an additional population. Our results showed that rs3746444 in mir-499 (allele C vs T: $\mathrm{OR}=1.33 ; 95 \% \mathrm{CI}=1.15^{-1} .54 ; P=1.2 \times 10^{-4}$ ) and rs4919510 in mir-608 (allele G vs C: OR $=1.27 ; 95 \% C I=1.13^{-1} .43 ; P=5.1 \times 10^{-5}$ ) were significantly associated with increased risk of lung cancer. Rs3746444 in mir-499 was also significantly associated with poor survival of lung cancer $(H R, 1.35 ; 95 \% C I, 1.15-1.58 ; P=0.0002)$. The expression levels of mir-499 and mir-608 were significantly lower than those of adjacent normal tissues $(P<0.0005)$, and the carriers of minor alleles have lower expression levels of mir-499 and mir-608 than those of major alleles $(P<0.001)$. These findings indicated that rs3746444 in mir-499 and rs4919510 in mir-608 might play a substantial role in the susceptibility to lung cancer.

\section{INTRODUCTION}

Lung cancer is the most common cancer in terms of both incidence and mortality worldwide, accounting for $13 \%$ of the total cancer cases and $18 \%$ of the cancer deaths [1-3]. It's estimated that there will be 0.221 million new cases of lung cancer and 0.158 million deaths in United States in 2015 [4]. According to the National Office for Cancer Prevention and Control in China, lung cancer ranked the third most prevalent cancers among Chinese population [5]. As a complex disease, carcinogenesis of lung cancer is strongly affected by genetic and environmental factors and their complex interactions [6-8]. 
MicroRNAs (miRNAs) are small (approximately 18-24 nt), noncoding RNAs with important functions in development, cell differentiation, and regulation of cell cycle and apoptosis [9]. They could influence tumorigenesis through their regulation of specific protooncogenes and tumor suppressor genes [10-16]. Studies have shown that miRNAs were extremely useful potential agents for clinical diagnostics as well as in personalized care for individual patients $[17,18]$. Polymorphisms in the miRNA pathway are emerging as powerful tools to study the cancer biology and have the potential to be used in cancer prognosis and diagnosis, especially for the genetic variants located in the mature miRNAs sequence, which could affect transcription of miRNA primary transcripts and processing of miRNA precursors $[19,20]$.

In current study, we hypothesized that genetic variants located in the mature miRNAs sequence could influence the susceptibility of lung cancer. Then we systematically searched miRBase (http://www.mirbase. org) for SNPs in miRNAs' mature sequences, and found 11 common (minor allele frequency $(\mathrm{MAF})>0.05$ ) SNPs existing in Chinese population (rs3746444 in mir-499, rs11237828 in mir-5579, rs9295535 in mir5689, rs12220909 in mir-4293, rs4919510 in mir608, rs13299349 in mir-3152, rs2168518 in mir-4513, rs10061133 in miR-449b, rs2620381 in mir-627, rs6513497 in mir-646, and rs8078913 in mir-4520a). The hypotheses were tested in a two-stage, case-control study, followed by some functional validations.

\section{RESULTS}

\section{Demographic variables and clinical information}

The selected characteristics of the lung cancer cases and healthy controls in two stages were described in Table 1. The cases and controls were well matched on the distribution of age and gender (all $p>0.05$ ). However, Significant differences in smoking status were observed between cases and controls $(p<0.001)$. More than $80 \%$ of the histology of the lung cancer patients are non-small-cell lung cancer in both stages.

\section{Association between the mature microRNAs' polymorphisms and risk of lung cancer}

In the discovery stage, the genotype distributions and lung cancer risk are presented in Table 2. All of the genotype distribution of these 11 SNPs in controls were in accordance with Hardy Weinberg equilibrium $(p>0.05)$. In the logistic regression analysis, rs3746444 in mir-499 and rs4919510 in mir-608 were independently associated with lung cancer risk after adjusting for age, sex, and smoking status. For the rs3746444 SNP, the C allele conferred 1.37-fold increased risk of lung cancer compared with the T allele (95\% CI: $1.09-1.71, P=0.005)$.
Individuals carrying $\mathrm{CC}$ genotype had an OR of 1.94 (95 \% CI: 1.10-3.40) compared with individuals with TT genotype. While for the rs4919510 SNP, the G allele conferred 1.36-fold increased risk of lung cancer compared with the C allele (95\% CI: $\left.1.14-1.63, P=8.02 \times 10^{-4}\right)$. Individuals carrying GG genotype had an OR of 1.78 (95 \% CI: 1.24-2.56) compared with individuals with $\mathrm{CC}$ genotype.

\section{Validation of the significant associations in stage II}

Then the two SNPs (rs3746444 in mir-499 and rs4919510 in mir-608) was evaluated in an independent dataset (Table 3). The trend was significantly replicated. When merged together, for rs3746444, C allele was significantly associated with a increased lung cancer risk when compared with T allele (OR: 1.33; 95\% CI: 1.15-1.54; $\left.P=1.2 \times 10^{-4}\right)$. The adjusted OR for the carriers with the CC genotype was $1.8(95 \% \mathrm{CI}: 1.25-2.60)$ and for those with the CT genotype was 1.25 (95\% CI: 1.04-1.49) compared with the TT genotype. For rs $4919510, \mathrm{G}$ allele was significantly associated with an increased lung cancer risk when compared with $\mathrm{C}$ allele (OR: 1.27 ; 95\% CI: 1.13-1.43; $P=5.1 \times 10^{-5}$ ). The adjusted OR for the carriers with the GG genotype was 1.57 (95\% CI: 1.24-1.99) and for those with the CG genotype was 1.24 (95\% CI: 1.04-1.48) compared with the $\mathrm{CC}$ genotype. To remove the possible effect modification of smoking status, we also conducted stratified analyses of the two SNPs. As shown in Table 4, the significant trend didn't change materially. To replicate the previous findings, we evaluated the relation between rs 3746444 and lung cancer survival. As shown in Table 5, rs3746444 in mir-499 was also significantly associated with poor survival of lung cancer (HR, $1.35 ; 95 \%$ CI $1.15-1.58 ; P=0.0002$ ).

\section{Functional validations of effect mir-499 and in mir-608}

First, to validate the functional effect of rs3746444 in mir-499 and rs4919510 in mir-608 on corresponding microRNAs in tissues of 500 lung cancer cases, qRTPCR was used to quantify the expression levels of mir499 and mir-608 in lung cancer tissues. As shown in Figure 1, the expression levels of mir-499 and mir-608 were significantly lower than those of adjacent normal tissues $(P<0.0005)$, and the carriers of minor alleles have significant lower expression levels of mir-499 and mir608 than those of major alleles $(P<0.001)$. Furthermore, the expression levels of mir-499 and mir-608 were tested in both the BEP2D cell line and its malignant transformant BERP35T1 cell line. Both mir-499 and mir-608 were down-expressed in BERP35T1, compared with BEP2D cell line (Figure 2). 
Table 1: Comparison of lung cancer patients and controls by selective characteristics

\begin{tabular}{|c|c|c|c|c|c|c|}
\hline \multirow[b]{2}{*}{ Variables } & \multicolumn{3}{|c|}{ Stage I } & \multicolumn{3}{|c|}{ Stage II } \\
\hline & $\begin{array}{c}\text { Cases } \\
(n=500)\end{array}$ & $\begin{array}{l}\text { Controls } \\
(n=500)\end{array}$ & $P$ value & $\begin{array}{c}\text { Cases } \\
(n=700)\end{array}$ & $\begin{array}{l}\text { Controls } \\
(n=700)\end{array}$ & $P$ value \\
\hline Age (years) & $58.2 \pm 4.7$ & $58.5 \pm 3.9$ & 0.272 & $60.1 \pm 5.4$ & $60.6 \pm 4.3$ & 0.056 \\
\hline Gender (male) & $391(78.2 \%)$ & $389(77.8 \%)$ & 0.879 & $518(74.0 \%)$ & $511(73.0 \%)$ & 0.672 \\
\hline \multicolumn{7}{|l|}{ Smoking status } \\
\hline Ever & $176(35.2 \%)$ & $69(13.7 \%)$ & $P<0.001$ & $260(37.1 \%)$ & $106(15.1 \%)$ & $P<0.001$ \\
\hline Never & $324(64.8 \%)$ & $431(86.3 \%)$ & & $440(62.9 \%)$ & $594(84.9 \%)$ & \\
\hline \multicolumn{7}{|l|}{ Histology } \\
\hline Small-cell lung cancer & $58(11.6 \%)$ & & & $89(12.7 \%)$ & & \\
\hline Non-small-cell lung cancer & $442(88.4 \%)$ & & & $611(87.3 \%)$ & & \\
\hline Adenocarcinoma & $202(40.4 \%)$ & & & $280(40.0 \%)$ & & \\
\hline Squamous cell & $151(30.2 \%)$ & & & $216(30.8 \%)$ & & \\
\hline Other NSCLC histology & $89(17.8 \%)$ & & & $115(16.5 \%)$ & & \\
\hline
\end{tabular}

A

Tissue Mir-499

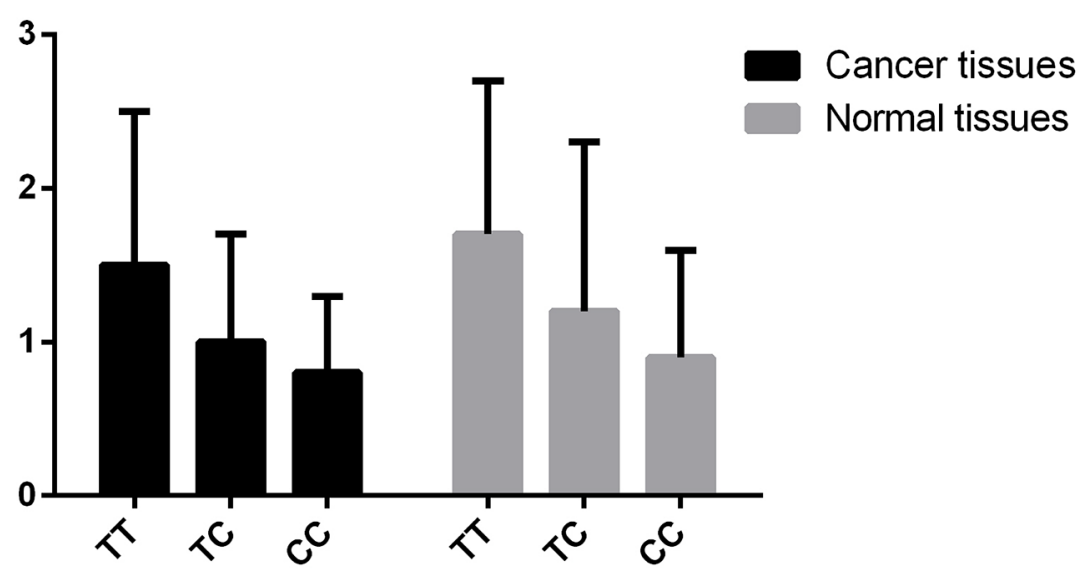

B

Tissue Mir-608

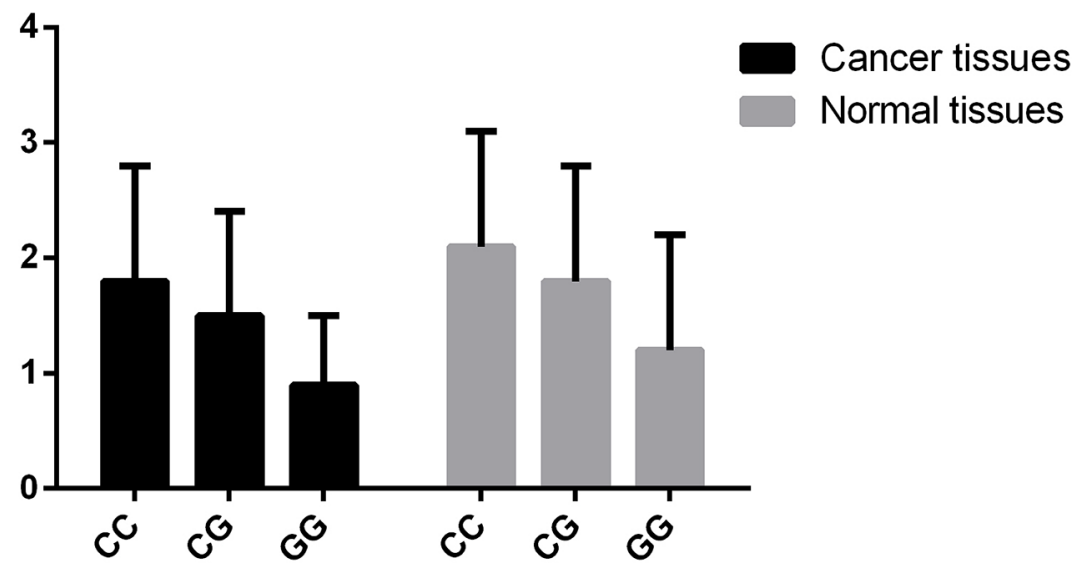

Figure 1: The expression level of mir-499 and mir-608 in lung cancer tissues. 
Table 2: Genotype frequencies of candidate SNPs and association with risk of lung cancer in Stage I

\begin{tabular}{|c|c|c|c|c|}
\hline Variants & $\begin{array}{c}\text { Cases } \\
(n=500)\end{array}$ & $\begin{array}{c}\text { Controls } \\
(n=500)\end{array}$ & $\begin{array}{c}\text { OR }^{1} \\
(95 \% \text { CIs) }\end{array}$ & $P$ value \\
\hline \multicolumn{5}{|l|}{ rs3746444 in mir-499 } \\
\hline TT & $316(63.2 \%)$ & $350(70.0 \%)$ & Reference & \\
\hline $\mathrm{TC}$ & $149(29.8 \%)$ & $130(26.0 \%)$ & $1.27(0.96-1.68)$ & 0.095 \\
\hline $\mathrm{CC}$ & $35(7.0 \%)$ & $20(4.0 \%)$ & $1.94(1.10-3.40)$ & 0.021 \\
\hline Additive model & & & $1.37(1.09-1.71)$ & 0.005 \\
\hline \multicolumn{5}{|l|}{ rs 11237828 in mir-5579 } \\
\hline TT & $212(42.4 \%)$ & $224(44.8 \%)$ & Reference & \\
\hline $\mathrm{TC}$ & $199(39.8 \%)$ & $211(42.2 \%)$ & $0.99(0.76-1.30)$ & 0.980 \\
\hline $\mathrm{CC}$ & $89(17.8 \%)$ & $65(13.0 \%)$ & $1,45(0.98-2.09)$ & 0.051 \\
\hline Additive model & & & $1.17(0.97-1.40)$ & 0.093 \\
\hline \multicolumn{5}{|l|}{ rs9295535 in mir-5689 } \\
\hline TT & $353(70.6 \%)$ & $348(69.6 \%)$ & Reference & \\
\hline $\mathrm{TC}$ & $114(22.8 \%)$ & $133(26.6 \%)$ & $0.84(0.63-1.13)$ & 0.256 \\
\hline $\mathrm{CC}$ & $33(6.6 \%)$ & $19(3.8 \%)$ & $1.71(0.96-3.05)$ & 0.068 \\
\hline Additive model & & & $1.06(0.84-1.34)$ & 0.597 \\
\hline \multicolumn{5}{|l|}{ rs12220909 in mir-4293 } \\
\hline GG & $279(55.8 \%)$ & $270(54.0 \%)$ & Reference & \\
\hline $\mathrm{GC}$ & $181(36.2 \%)$ & $195(39.0 \%)$ & $0.89(0.69-1.17)$ & 0.423 \\
\hline $\mathrm{CC}$ & $40(8.0 \%)$ & $35(7.0 \%)$ & $1.10(0.68-1.79)$ & 0.683 \\
\hline Additive model & & & $0.98(0.80-1.19)$ & 0.839 \\
\hline \multicolumn{5}{|l|}{ rs4919510 in mir-608 } \\
\hline $\mathrm{CC}$ & $178(35.6 \%)$ & $220(44.0 \%)$ & Reference & \\
\hline $\mathrm{CG}$ & $221(44.2 \%)$ & $210(42.0 \%)$ & $1.30(0.99-1.71)$ & 0.049 \\
\hline GG & $101(20.2 \%)$ & $70(14.0 \%)$ & $1.78(1.24-2.56)$ & 0.002 \\
\hline Additive model & & & $1.36(1.14-1.63)$ & $8.02 \times 10^{-4}$ \\
\hline \multicolumn{5}{|l|}{ rs13299349 in mir-3152 } \\
\hline GG & $380(76.0 \%)$ & $363(72.6 \%)$ & Reference & \\
\hline GA & $106(21.2 \%)$ & $120(24.0 \%)$ & $0.84(0.63-1.14)$ & 0.264 \\
\hline $\mathrm{AA}$ & $14(2.8 \%)$ & $17(3.4 \%)$ & $0.79(0.38-1.61)$ & 0.514 \\
\hline Additive model & & & $0.85(0.66-1.09)$ & 0.203 \\
\hline \multicolumn{5}{|l|}{ rs2168518 in mir-4513 } \\
\hline GG & $288(57.6 \%)$ & $278(55.6 \%)$ & Reference & \\
\hline GA & $191(38.2 \%)$ & $200(40.0 \%)$ & $0.92(0.71-1.19)$ & 0.536 \\
\hline AA & $21(4.2 \%)$ & $22(4.4 \%)$ & $0.92(0.49-1.71)$ & 0.796 \\
\hline Additive model & & & $0.94(0.77-1.16)$ & 0.564 \\
\hline \multicolumn{5}{|l|}{ rs 10061133 in miR-449b } \\
\hline $\mathrm{AA}$ & $278(55.6 \%)$ & $263(52.6 \%)$ & Reference & \\
\hline GA & $182(36.4 \%)$ & $191(38.2 \%)$ & $0.90(0.69-1.17)$ & 0.441 \\
\hline GG & $40(8.0 \%)$ & $46(9.2 \%)$ & $0.82(0.52-1.30)$ & 0.401 \\
\hline Additive model & & & $0.90(0.74-1.09)$ & 0.292 \\
\hline rs2620381 in mir-627 & & & & \\
\hline
\end{tabular}




$\begin{array}{ccc}\text { AA } & 335(67.0 \%) & 350(70.0 \%) \\ \text { AC } & 140(28.0 \%) & 131(26.2 \%) \\ \text { CC } & 25(5.0 \%) & 19(3.8 \%)\end{array}$

Additive model

rs6513497 in mir-646

$\begin{array}{ccc}\text { TT } & 335(67.0 \%) & 340(68.0 \%) \\ \text { TG } & 145(29.0 \%) & 137(27.4 \%) \\ \text { GG } & 20(4.0 \%) & 23(4.6 \%)\end{array}$

Additive model

rs8078913 in mir-4520a

\begin{tabular}{rcccc} 
TT & $234(46.8 \%)$ & $233(46.6 \%)$ & Reference & \\
TC & $213(42.6 \%)$ & $227(45.4 \%)$ & $0.93(0.72-1.21)$ & 0.609 \\
CC & $53(20.6 \%)$ & $40(8.0 \%)$ & $1.32(0.84-2.06)$ & 0.225 \\
Additive model & & & $1.06(0.87-1.28)$ & 0.563 \\
\hline
\end{tabular}

1adjusted for age, gender, and smoking status.

Table 3: Genotype frequencies of selected SNPs and association with risk of lung cancer in Stage II and the merged results

\begin{tabular}{ccccc}
\hline Variants & $\begin{array}{c}\text { Cases } \\
(n=700)\end{array}$ & $\begin{array}{c}\text { Controls } \\
(n=700)\end{array}$ & $\begin{array}{c}\text { OR }^{1} \\
(95 \% \text { CIs })\end{array}$ & $P$ value \\
\hline rs3746444 in mir-499 & & & \\
\hline
\end{tabular}

rs3746444 in mir-499

Stage II

$\begin{array}{ccc}\text { TT } & 461(65.8 \%) & 500(71.4 \%) \\ \text { TC } & 195(27.9 \%) & 172(24.6 \%) \\ \text { CC } & 44(6.3 \%) & 28(4.0 \%)\end{array}$

Additive model

Merged results

$\begin{array}{cc}\text { TT } & 777(64.8 \%) \\ \text { TC } & 344(28.7 \%) \\ \text { CC } & 79(6.5 \%)\end{array}$

$$
\begin{gathered}
850(70.8 \%) \\
302(25.2 \%) \\
48(4.0 \%)
\end{gathered}
$$

Additive model

rs4919510 in mir-608

Stage II

$\begin{array}{ll}\text { CC } & 271(38.7 \%) \\ \text { CG } & 310(44.3 \%) \\ \text { GG } & 119(17.0 \%)\end{array}$

$$
\begin{gathered}
310(44.3 \%) \\
295(42.2 \%) \\
95(13.5 \%)
\end{gathered}
$$

Additive model

Merged results

$$
\begin{array}{ll}
\text { CC } & 449(37.4 \%) \\
\text { CG } & 531(44.3 \%) \\
\text { GG } & 220(18.3 \%)
\end{array}
$$

$530(44.2 \%)$

$505(42.1 \%)$

$165(13.7 \%)$

Reference

$\begin{array}{ll}1.23(0.97-1.56) & 0.080 \\ 1.70(1.05-2.77) & \mathbf{0 . 0 3 1} \\ 1.30(1.07-1.58) & \mathbf{0 . 0 0 7}\end{array}$

Additive model

${ }^{1}$ adjusted for age, gender, and smoking status.

Reference

$\begin{array}{cc}1.25(1.04-1.49) & \mathbf{0 . 0 1 8} \\ 1.80(1.25-2.60) & \mathbf{0 . 0 0 2} \\ 1.33(1.15-1.54) & 1.2 \times 10^{-4}\end{array}$

Reference

$\begin{array}{ll}1.20(0.96-1.51) & 0.089 \\ 1.43(1.04-1.96) & \mathbf{0 . 0 2 5} \\ 1.21(1.04-1.41) & \mathbf{0 . 0 1 4}\end{array}$

Reference

$1.24(1.04-1.48) \quad \mathbf{0 . 1 5}$

$1.57(1.24-1.99) \quad 1.8 \times 10^{-4}$

$1.27(1.13-1.43) \quad 5.1 \times 10^{-5}$ 
Table 4: Stratified analyses of selected SNPs and association with risk of lung cancer by smoking status

\begin{tabular}{|c|c|c|c|c|c|c|c|c|}
\hline \multirow[b]{2}{*}{ SNP } & \multicolumn{4}{|c|}{ Smokers } & \multicolumn{4}{|c|}{ Non-smokers } \\
\hline & $\begin{array}{c}\text { Cases } \\
(n=436)\end{array}$ & $\begin{array}{l}\text { Controls } \\
(n=175)\end{array}$ & $\begin{array}{c}\text { OR }^{1} \\
(95 \% \text { CIs })\end{array}$ & $P$ value & $\begin{array}{c}\text { Cases } \\
(n=764)\end{array}$ & $\begin{array}{c}\text { Controls } \\
(n=1025)\end{array}$ & $\begin{array}{c}\text { OR }^{1} \\
(95 \% \mathrm{CIs})\end{array}$ & $P$ value \\
\hline \multicolumn{9}{|l|}{ rs3746444 } \\
\hline $\mathrm{TT}$ & $\begin{array}{c}279 \\
(64.0 \%)\end{array}$ & $\begin{array}{c}124 \\
(71.0 \%)\end{array}$ & Reference & & $\begin{array}{c}498 \\
(65.2 \%)\end{array}$ & $726(70.8 \%)$ & Reference & \\
\hline $\mathrm{TC}$ & $\begin{array}{c}122 \\
(28.0 \%)\end{array}$ & $44(25.0 \%)$ & $\begin{array}{c}1.23 \\
(0.82-1.84)\end{array}$ & 0.311 & $\begin{array}{c}222 \\
(29.1 \%)\end{array}$ & $258(25.2 \%)$ & $\begin{array}{c}1.25 \\
(1.01-1.55)\end{array}$ & 0.036 \\
\hline $\mathrm{CC}$ & $35(8 \%)$ & $7(4.0 \%)$ & $\begin{array}{c}2.22 \\
(0.98-5.04)\end{array}$ & 0.056 & $44(5.7 \%)$ & $41(4.0 \%)$ & $\begin{array}{c}1.56 \\
(1.01-2.42)\end{array}$ & 0.045 \\
\hline $\begin{array}{r}\text { Additive } \\
\text { model }\end{array}$ & & & $\begin{array}{c}1.42 \\
(1.03-1.96)\end{array}$ & 0.029 & & & $\begin{array}{c}1.28 \\
(1.08-1.52)\end{array}$ & $4.4 \times 10^{-3}$ \\
\hline \multicolumn{9}{|l|}{ rs4919510 } \\
\hline $\mathrm{CC}$ & $\begin{array}{c}165 \\
(37.9 \%)\end{array}$ & $77(44.0 \%)$ & Reference & & $\begin{array}{c}284 \\
(37.2 \%)\end{array}$ & $453(44.2 \%)$ & Reference & \\
\hline $\mathrm{CG}$ & $\begin{array}{c}192 \\
(44.0 \%)\end{array}$ & $74(42.3 \%)$ & $\begin{array}{c}2.03 \\
(1.33-3.10)\end{array}$ & $9.3 \times 10^{-4}$ & $\begin{array}{c}339 \\
(44.4 \%)\end{array}$ & $431(42.0 \%)$ & $\begin{array}{c}1.25 \\
(1.02-1.54)\end{array}$ & 0.031 \\
\hline GG & $79(18.1 \%)$ & $24(13.7 \%)$ & $\begin{array}{c}1.54 \\
(0.91-2.61)\end{array}$ & 0.112 & $\begin{array}{c}141 \\
(18.4 \%)\end{array}$ & $141(13.8 \%)$ & $\begin{array}{c}1.59 \\
(1.21-2.10)\end{array}$ & $8.9 \times 10^{-4}$ \\
\hline $\begin{array}{r}\text { Additive } \\
\text { model }\end{array}$ & & & $\begin{array}{c}1.44 \\
(1.08-1.91)\end{array}$ & 0.011 & & & $\begin{array}{c}1.28 \\
(1.12-1.47)\end{array}$ & $3.3 \times 10^{-3}$ \\
\hline
\end{tabular}

${ }^{1}$ adjusted for age, and gender.

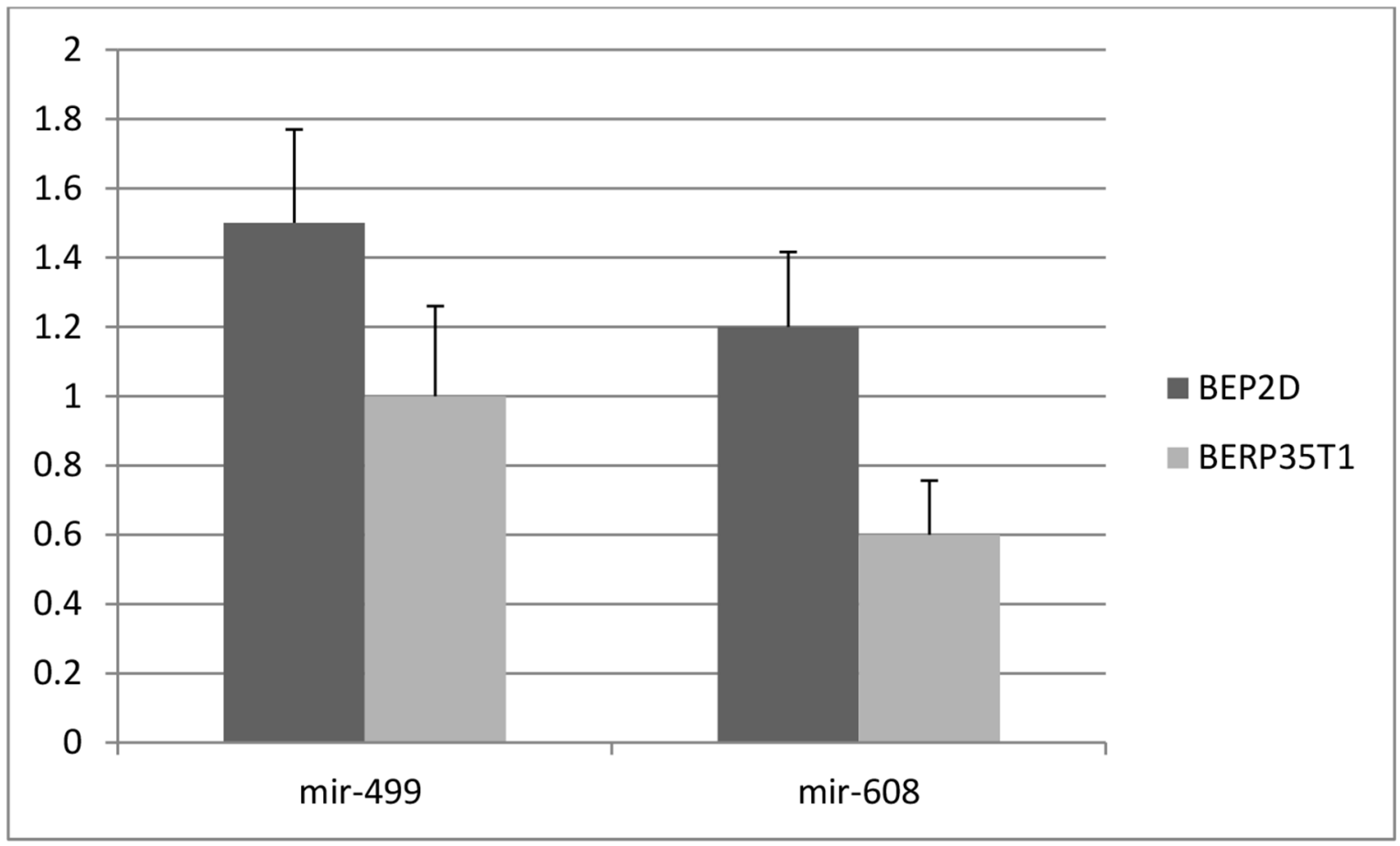

Figure 2: The expression level of mir-499 and mir-608 in cell lines. 
Table 5: Associations between mir-499 rs3746444 and lung cancer survival

\begin{tabular}{rcccc}
\hline \multicolumn{1}{l}{ Variants } & $\begin{array}{c}\text { Lung cancer } \\
\text { patients }\end{array}$ & Death & $\begin{array}{c}\text { Cox model, adjusted } \\
\text { HR (95\% CI) }\end{array}$ & $\boldsymbol{P}^{\mathbf{9} \text { value }}$ \\
\hline rs3746444 in mir-499 & & & & \\
TT & 769 & 621 & Reference & \\
TC & 340 & 298 & $1.22(1.07-1.39)$ & \\
CC & 77 & 69 & $1.97(1.19-3.17)$ & \\
Additive model & & & $1.35(1.15-1.58)$ & $\mathbf{0 . 0 0 0 2}$ \\
\hline
\end{tabular}

${ }^{1}$ The Cox regression analysis was adjusted for age, gender, smoking, stage, surgery, chemotherapy, and radiotherapy status.

\section{DISCUSSION}

In this two-stage, case-control study with a total of 1,200 lung cancer cases and 1,200 controls from Han Chinese population, we investigated the associations of 11 common SNPs located in miRNAs' mature sequences with risk of lung cancer. Our results showed that rs3746444 in mir-499 and rs4919510 in mir-608 were significantly associated with increased risk of lung cancer. Rs3746444 in mir-499 was also significantly associated with poor survival of lung cancer. We also found that the expression levels of mir-499 and mir-608 were significantly lower than those of adjacent normal tissues, while the carriers of minor alleles have lower expression levels of mir-499 and mir-608 than those of major alleles. To our knowledge, this is the first study to use multilevel approaches, including genetic association study and gene expression analyses in plasma and tissues, to systematically investigate the effect of genetic variants located in mature microRNAs in relation to etiology of lung cancer.

MicroRNAs have becoming focused circulating biomarkers, given their potential in the translational area and the role of representative readouts of both primary tumor and metastatic deposits [9, 21-23]. Genetic variants located in Mature MicroRNAs have been also explored to discover potential clues for pathogenesis of many diseases [24-30]. Recently, Zhang et al [29] evaluated five SNPs in the mature sequence of microRNAs, and found miR-449b rs10061133 and miR-4293 rs12220909 polymorphisms are associated with decreased esophageal squamous cell carcinoma. Qiu et al [25] evaluated 8 SNPs in the mature sequence of microRNAs, and the results showed that rs4919510 in mature mir-608 sequence is associated with an increased risk of nasopharyngeal carcinoma. Ryan et al [31] found the GG genotype of rs4919510 in mir-608 was associated with an increased risk of death of colorectal cancer. In current study, we also identified rs4919510 in mir-608 was significantly associated with increased risk of lung cancer. Functional validation also confirmed that minor allele $\mathrm{G}$ of rs 4919510 could increase the expression of mir-608, both in plasma and tissues.

Association of Mir-499 rs3746444 with cancer risk has been fully explored [32-36]. A recent meta- analysis showed that miR-499 rs3746444 polymorphism contributed to increased risk of many cancers (GG versus $\mathrm{AA}: \mathrm{OR}=1.24,95 \% \mathrm{CI}$ : $1.01-1.52 ; \mathrm{G}$ versus $\mathrm{A}$ : $\mathrm{OR}=1.11,95 \% \mathrm{CI}: 1.01-1.23$ ) [32]. This is consistent with our results, which revealed that rs3746444 in mir499 was significantly associated with increased risk of lung cancer, and the carriers of minor allele $\mathrm{C}$ have higher expression levels of mir-499 than those of major allele $\mathrm{T}$. Very recently, Qiu et al [37] also reported that rs3746444 could contribute to poor prognosis by modulating cancerrelated genes' expression and thus involve tumorigenesis and anti-chemotherapy. Furthermore, the in silico functional analysis of rs3746444 and rs4919510 was conducted by miRVaS: a tool to predict the impact of genetic variants on miRNAs [38]. The results showed that rs3746444 was located at mature3p $(a+5)$ seed of mir-499. It could change the hairpin structure and affect the mature of the mir-499. While rs4919510 was located at mature $5 p(a+23)$ of mir-608, could also change the hairpin structure and affect the mature of the mir-608. All the evidence presented above validated the functions of genetic variants located in mature microRNAs in relation to etiology of cancers.

In summary, our study showed that rs3746444 in mir-499 and rs4919510 in mir-608 could contribute to the carcinogenesis of lung cancer. Although the existence of some limitations, like possible selection bias in casecontrol study, and limited sample size for interaction analyses, our study still strongly supports the contribution of causative variants located in the mature microRNAs for lung cancer through multilevel approach validations. Further studies with functional and mechanism characterizations, are warranted to provide additional definitive evidence.

\section{MATERIALS AND METHODS}

\section{Study Subjects}

This study consisted of 500 patients with newly diagnosed lung cancer and 500 cancer-free controls in stage I, while 700 lung cancer cases and 700 cancer-free controls in stage II. Patients, which were 
histopathologically confirmed lung cancer cases, were consecutively recruited between October 2009 and December 2013. While controls were randomly selected from a healthy screening program in the same region and the same population during the same time period as the cases were enrolled. Demographic information were collected for each participant according to a unified procedure. For each participant, approximately $5 \mathrm{ml}$ whole blood was obtained to extract genomic DNA for genotyping analysis after the face to face interview. This study conformed to the principles outlined in the Declaration of Helsinki and was approved by appropriate institutional review board. Written consent was obtained from all participants of this study.

\section{Genotyping}

Genomic DNA was extracted from 3-ml of peripheral blood sample using the QIAamp DNA extraction kit (QIAGEN). The candidate SNPs were genotyped using TaqMan real-time polymerase chain reaction (PCR) Assay (Applied Biosystems, Foster city, $\mathrm{CA}$ ) without the information of the case or control status of the subjects. We used the ABI Prism 7900HT Sequence Detection System analyze the endpoint fluorescence. Quality control was monitored by including 5\% duplicate and negative control, with the $100 \%$ concurrence rate of the duplicate sets. The average call rate for the candidate SNPs genotyped was $>99.9 \%$. All related primers were provided in Supplemental Table 1.

\section{Cell culture}

The BEP2D cell line (a human papillomavirus 18-immortalized human bronchial epithelial cell line), and The BERP35T1 malignant transformant cell line which were derived from the BEP2D cell line, were cultured to investigate the function of miR-499 and miR-608.

\section{RNA extraction and Quantification of miRNA by qRT-PCR}

Total RNA was extracted from tumor tissues and adjacent normal tissues of 500 cases of lung cancer using Trizol reagent following manufacturer's protocol. Then the amounts of miRNAs were quantified by qRT-PCR using the human TaqMan MicroRNA Assay Kit (Applied Biosystems, Foster City, CA, USA). The expression of miRNAs from tissue samples was normalized using the $2 \mathrm{Ct}$ method relative to U6 small nuclear RNA (RNU6B). The relative gene expression levels were determined using the comparative threshold cycle $\left(2^{-\Delta \Delta \mathrm{CT}}\right)$ method.

\section{Statistical Analysis}

Pearson's $\mathrm{x}^{2}$ test or $t$-test were used to examine differences between cases and controls in the distribution of demographic characteristics. To evaluate the associations between the genotypes and lung cancer risk, odds ratios (ORs) and 95\% confidence intervals (CIs) were calculated by unconditional logistic regression analysis with adjustment for age, gender, and smoking status. The Hardy-Weinberg equilibrium (HWE) for the distribution of each variant was evaluated using the goodness of-fit $\chi 2$ test by comparing the observed genotype frequencies with the expected ones in the controls. All statistical analyses were conducted by SPSS v18.0 software, while a two-tailed $P<0.05$ was used as the criterion of statistical significance.

\section{ACKNOWLEDGMENTS AND FUNDING}

Sincere acknowledgments should be given to all subjects who participated in this project.

\section{CONFLICT OF INTERESTS}

None to declare.

\section{REFERENCES}

1. Brunelli L, Caiola E, Marabese M, Broggini M, Pastorelli R. Capturing the metabolomic diversity of KRAS mutants in non-small-cell lung cancer cells. Oncotarget. 2014; 5:4722-4731. doi: 10.18632/oncotarget.1958.

2. Walsh KM, Amos CI, Wenzlaff AS, Gorlov IP, Sison JD, Wu X, Spitz MR, Hansen HM, Lu EY, Wei C, Zhang H, Chen W, Lloyd SM, et al. Association study of nicotinic acetylcholine receptor genes identifies a novel lung cancer susceptibility locus near CHRNA1 in AfricanAmericans. Oncotarget. 2012; 3:1428-1438. doi: 10.18632/ oncotarget.746.

3. Zhong R, Liu L, Zou L, Zhu Y, Chen W, Zhu B, Shen N, Rui R, Long L, Ke J, Lu X, Zhang T, Zhang Y, et al. Genetic variations in TERT-CLPTM1L locus are associated with risk of lung cancer in Chinese population. Mol Carcinog. 2013; 52 Suppl 1:E118-126.

4. Siegel RL, Miller KD, Jemal A. Cancer statistics, 2015. CA Cancer J Clin. 2015; 65:5-29.

5. Zheng R, Zeng H, Zhang S, Chen T, Chen W. National estimates of cancer prevalence in China, 2011. Cancer Lett. 2015.

6. Cooper WA. Preface-molecular genetics of lung cancer. Translational lung cancer research. 2015; 4:109.

7. Rosell R, Bivona TG, Karachaliou N. Genetics and biomarkers in personalisation of lung cancer treatment. Lancet. 2013; 382:720-731.

8. Young R, Hopkins R, Etzel C, El-Zein R. Genetics of lung cancer susceptibility and COPD. Lancet Oncol. 2011; 12:622-623. 
9. Garzon R, Calin GA, Croce CM. MicroRNAs in Cancer. Annu Rev Med. 2009; 60:167-179.

10. Zhu J, Wang S, Zhang W, Qiu J, Shan Y, Yang D, Shen B. Screening key microRNAs for castration-resistant prostate cancer based on miRNA/mRNA functional synergistic network. Oncotarget. 2015; 6:43819-30. doi: 10.18632/ oncotarget.6102.

11. Sun Y, Ai X, Shen S, Lu S. NF-kappaB-mediated miR-124 suppresses metastasis of non-small-cell lung cancer by targeting MYO10. Oncotarget. 2015; 6:8244-8254. doi: 10.18632/oncotarget.3135.

12. Salah Z, Arafeh R, Maximov V, Galasso M, Khawaled S, Abou-Sharieha S, Volinia S, Jones KB, Croce CM, Aqeilan RI. miR-27a and miR-27a* contribute to metastatic properties of osteosarcoma cells. Oncotarget. 2015; 6:4920-4935. doi: 10.18632/oncotarget.3025.

13. Han K, Chen X, Bian N, Ma B, Yang T, Cai C, Fan Q, Zhou Y, Zhao TB. MicroRNA profiling identifies MiR195 suppresses osteosarcoma cell metastasis by targeting CCND1. Oncotarget. 2015; 6:8875-8889. doi: 10.18632/ oncotarget.3560.

14. Cheng CW, Chen PM, Hsieh YH, Weng CC, Chang CW, Yao CC, Hu LY, Wu PE, Shen CY. Foxo3a-mediated overexpression of microRNA-622 suppresses tumor metastasis by repressing hypoxia-inducible factor-1alpha in erk-responsive of lung cancer. Oncotarget. 2015; 6: 44222-38. doi: 10.18632/oncotarget.5826.

15. Carvalheira G, Nozima BH, Cerutti JM. microRNA106b-mediated down-regulation of $\mathrm{C} 1$ orf 24 expression induces apoptosis and suppresses invasion of thyroid cancer. Oncotarget. 2015; 6:28357-28370. doi: 10.18632/ oncotarget.4947.

16. Yang WB, Chen PH, Hsu Ts, Fu TF, Su WC, Liaw H, Chang WC, Hung JJ. Spl-mediated microRNA-182 expression regulates lung cancer progression. Oncotarget. 2014; 5:740-753. doi: 10.18632/oncotarget.1608.

17. Tie Y, Liu B, Fu H, Zheng X. Circulating miRNA and cancer diagnosis. Sci China C Life Sci. 2009; 52:1117-1122.

18. Paranjape T, Slack FJ, Weidhaas JB. MicroRNAs: tools for cancer diagnostics. Gut. 2009; 58:1546-1554.

19. Saunders MA, Liang H, Li WH. Human polymorphism at microRNAs and microRNA target sites. Proceedings of the National Academy of Sciences of the United States of America. 2007; 104:3300-3305.

20. Mishra PJ, Bertino JR. MicroRNA polymorphisms: the future of pharmacogenomics, molecular epidemiology and individualized medicine. Pharmacogenomics. 2009; 10:399-416.

21. Bartel DP. MicroRNAs: target recognition and regulatory functions. Cell. 2009; 136:215-233.

22. Filipowicz W, Bhattacharyya SN and Sonenberg N. Mechanisms of post-transcriptional regulation by microRNAs: are the answers in sight? Nat Rev Genet. 2008; 9:102-114.
23. Ruvkun G. Clarifications on miRNA and cancer. Science. 2006; 311:36-37.

24. Zhang B, Wang A, Xia C, Lin Q, Chen C. A single nucleotide polymorphism in primary-microRNA-146a reduces the expression of mature microRNA-146a in patients with Alzheimer's disease and is associated with the pathogenesis of Alzheimer's disease. Mol Med Rep. 2015; 12:4037-4042.

25. Qiu F, Yang L, Zhang L, Yang X, Yang R, Fang W, Wu D, Chen J, Xie C, Huang D, Zhou Y, Lu J. Polymorphism in mature microRNA-608 sequence is associated with an increased risk of nasopharyngeal carcinoma. Gene. 2015; 565:180-186.

26. Huang AJ, Yu KD, Li J, Fan L, Shao ZM. Polymorphism rs4919510:C $>\mathrm{G}$ in mature sequence of human microRNA-608 contributes to the risk of HER2-positive breast cancer but not other subtypes. PLoS One. 2012; 7:e35252.

27. Christensen BC, Avissar-Whiting M, Ouellet LG, Butler RA, Nelson HH, McClean MD, Marsit CJ, Kelsey KT. Mature microRNA sequence polymorphism in MIR196A2 is associated with risk and prognosis of head and neck cancer. Clin Cancer Res. 2010; 16:3713-3720.

28. Xu B, Feng NH, Li PC, Tao J, Wu D, Zhang ZD, Tong N, Wang JF, Song NH, Zhang W, Hua LX, Wu HF. A functional polymorphism in Pre-miR-146a gene is associated with prostate cancer risk and mature miR-146a expression in vivo. Prostate. 2010; 70:467-472.

29. Zhang P, Wang J, Lu T, Wang X, Zheng Y, Guo S, Yang Y, Wang M, Kolluri VK, Qiu L, Shen F, Fan L, Li J, et al. miR-449b rs10061133 and miR-4293 rs12220909 polymorphisms are associated with decreased esophageal squamous cell carcinoma in a Chinese population. Tumour Biol. 2015; 36:8789-95.

30. Zheng J, Deng J, Xiao M, Yang L, Zhang L, You Y, Hu M, Li N, Wu H, Li W, Lu J, Zhou Y. A sequence polymorphism in miR-608 predicts recurrence after radiotherapy for nasopharyngeal carcinoma. Cancer Res. 2013; 73:51515162.

31. Ryan BM, McClary AC, Valeri N, Robinson D, Paone A, Bowman ED, Robles AI, Croce C, Harris CC. rs4919510 in hsa-mir-608 is associated with outcome but not risk of colorectal cancer. PLoS One. 2012; 7:e36306.

32. Xu Z, Zhang E, Duan W, Sun C, Bai S, Tan X. The association between miR-499 polymorphism and cancer susceptibility: a meta-analysis. OncoTargets and therapy. 2015; 8:2179-2186.

33. Nikolic Z, Savic Pavicevic D, Vucic N, Cidilko S, Filipovic N, Cerovic S, Vukotic V, Romac S, Brajuskovic G. Assessment of association between genetic variants in microRNA genes hsa-miR-499, hsa-miR-196a2 and hsamiR-27a and prostate cancer risk in Serbian population. Exp Mol Pathol. 2015; 99:145-150.

34. Liu X, Xu B, Li S, Zhang B, Mao P, Qian B, Guo L, Ni P. Association of SNPs in miR-146a, miR-196a2, and miR- 
499 with the risk of endometrial/ovarian cancer. Acta Biochim Biophys Sin (Shanghai). 2015; 47:564-566.

35. Jiang SG, Chen L, Tang JH, Zhao JH, Zhong SL. Lack of association between Hsa-Mir-499 rs3746444 polymorphism and cancer risk: meta-analysis findings. Asian Pac J Cancer Prev. 2015; 16:339-344.

36. Chen C, Yang S, Chaugai S, Wang Y, Wang DW. Metaanalysis of Hsa-mir-499 polymorphism (rs3746444) for cancer risk: evidence from 31 case-control studies. BMC Med Genet. 2014; 15:126.
37. Qiu F, Yang L, Ling X, Yang R, Yang X, Zhang L, Fang W, Xie C, Huang D, Zhou Y, Lu J. Sequence Variation in Mature MicroRNA-499 Confers Unfavorable Prognosis of Lung Cancer Patients Treated with Platinum-Based Chemotherapy. Clin Cancer Res. 2015; 21:1602-1613.

38. Cammaerts S, Strazisar M, Dierckx J, Del Favero J, De Rijk P. miRVaS: a tool to predict the impact of genetic variants on miRNAs. Nucleic Acids Res. 2016; 44:e23. 